\title{
Knowledge and beliefs concerning evidence-based practice amongst complementary and alternative medicine health care practitioners and allied health care professionals: A questionnaire survey Julie Hadley*1, Ismail Hassan ${ }^{1}$ and Khalid S Khan ${ }^{1,2}$
}

\author{
Address: ${ }^{1 T h e}$ Education Resource Centre. Birmingham Women's Health Care NHS Trust, Edgbaston, Birmingham, B15 2TG, UK and ${ }^{2}$ The \\ University of Birmingham, Edgbaston, Birmingham, B15 2TT, UK \\ Email: Julie Hadley* - Julie.Hadley@staffs.ac.uk; Ismail Hassan - imhassan@doctors.org.uk; Khalid S Khan - k.s.khan@bham.ac.uk \\ * Corresponding author
}

Published: 23 July 2008

BMC Complementary and Alternative Medicine 2008, 8:45 doi:I0.1 186/1472-6882-8-45
Received: 14 September 2007

Accepted: 23 July 2008

This article is available from: http://www.biomedcentral.com/l472-6882/8/45

(c) 2008 Hadley et al; licensee BioMed Central Ltd.

This is an Open Access article distributed under the terms of the Creative Commons Attribution License (http://creativecommons.org/licenses/by/2.0), which permits unrestricted use, distribution, and reproduction in any medium, provided the original work is properly cited.

\begin{abstract}
Background: Evidence-based practice (EBP) has become an important competency in many allied and complementary and alternative medicine (CAM) health care practitioners' professional standards of proficiency.

Methods: To compliment an EBP course for allied health care professionals and CAM practitioners, we undertook a questionnaire survey to assess learning needs. We developed a questionnaire to measure allied health care professionals and CAM practitioners' basic knowledge, skills and beliefs concerning the main principles of EBP. The questionnaires were administered to all attendees of one-day EBP workshops.

Results: During 2004-5 we surveyed 193 allied health care professionals and CAM practitioners who attended one-day EBP courses prior to commencement of teaching. Of the respondents I2I (62.7\%) were allied health care professionals and 65 (33.7\%) practitioners stated that they work in the CAM field Our survey found that the majority of the respondents had not previously attended a literature appraisal skills workshop $(87.3 \%)$ or received formal training in research methods $(69.9 \%)$, epidemiology $(91.2 \%)$ or statistics $(80.8 \%)$. Furthermore, $67.1 \%$ of practitioners specified that they felt that they had not had adequate training in EBM and they identified that they needed more training and education in the principles of EBM (86.7\%). Differences in knowledge and beliefs concerning EBP amongst allied and CAM practitioners were found and length of time since qualification was also found to be an important factor in practitioner's beliefs. More CAM practitioners compared to allied health professionals accessed educational literature via the Internet $(95.3 \%$ v $68.1 \%, p=0.008)$. Whilst, practitioners with more than II years experience felt that original research papers were far more confusing $(p=0.02)$ than their less experienced colleagues.
\end{abstract}

Conclusion: The results demonstrate that practitioner's learning needs do vary according to the type of profession, time since graduation and prior research experience. Our survey findings are exploratory and will benefit from further replication, however, we do believe that they warrant consideration by allied health care and CAM tutors and trainers when planning EBP teaching curricula as it is important to tailor teaching to meet the needs of specific subgroups of trainees to ensure that specific learning needs are met. 


\section{Background}

Evidence-Based Practice (EBP) requires that decisions about health care are based on the best available, current, valid and relevant evidence. These decisions should be made by those receiving care, informed by the tacit and explicit knowledge of those providing care [1]. Regardless of speciality, teaching of evidence-based medicine (EBM) or EBP has become part of the core medical training in the United Kingdom [2] and has also become recognised as an important competency in many allied [3-10] and complementary (CAM) [11-13] health care practitioners' professional standards of proficiency. Furthermore, a report from the UK House of Lords [14] has recommended that that every therapist working in CAM should have a clear understanding of the principles of evidence-based healthcare.

The opportunities for CAM practitioners to learn the principles of EBP are limited. We found no courses available in our region. As both allied health care professionals and CAM practitioners are not catered for in traditional EBM postgraduate medical training, we developed an EBP course for allied health care professionals and CAM practitioners. The course was designed so that it had a core curriculum, which could be adapted specifically to the individual needs of the students [15]. To ensure that relevant teaching and learning opportunities were realised, a needs assessment exercise was undertaken, as recommended by Harden [16] as an essential criteria which should be carried out when designing and developing any course and particularly because EBP has not been a mandatory requirement of their training until recently. The findings of such an exercise can provide critical evidence for development and tailoring of EBP curricula improving the effectiveness of teaching. We undertook a needs assessment exercise using a questionnaire survey of allied health care professionals and CAM practitioners' knowledge, skills and beliefs regarding EBP in the West Midlands region. This allowed us the opportunity to compare and contrast different needs of groups according to specialty and time since qualification and to tailor our course to meet their specific needs

\section{Methods}

During 2004-5 we surveyed 193 allied health care professionals and CAM practitioners who attended one-day EBP courses prior to commencement of teaching. Allied health care professionals included Physiotherapists, Chiropodists, Dentists, Nurses, Midwives, Sport injuries specialists, Nursing assistants and Pharmacists. CAM practitioners included Osteopaths, Chiropractors, Alexander technique practitioners, Acupuncturists, Herbalists, Feng Chui practitioners, Homoeopaths, Hypnotherapists, Shiatsu practitioners, and Reflexologists. Invitations were sent out to all CAM practitioners and allied health care professionals listed in a database of all registered practitioners that we developed by interrogating the West Midlands regional directory and relevant professional associations. In total 859, CAM practitioners and allied health care professionals were approached and 193 $(22.5 \%)$ completed the questionnaire. Attendance to these courses was free and not mandatory. The courses were funded from a grant received from the Learning and Skills Council and European Social Fund (European Union Grant LSE31068WM2). The study was planned prospectively using recommended methods for educational needs analyses[16] and questionnaire surveys [17]. Ethical approval for the study was not required. Participants were made aware of the purpose of the survey, the anonymous nature of the dataset generated and the option to not respond if they so wished. This information served as the basis for an informed consent from each respondent.

We developed a questionnaire to measure allied health care professionals and CAM practitioners' basic knowledge, skills and beliefs concerning the main principles of EBP including questions from previously published and validated questionnaires [18-21]. The questionnaire included questions relating to the practitioners' self assessment of their literature searching behaviour, their self perceived knowledge of their own critical appraisal skills and beliefs. Multiple choice answers and six-point Likert scales were used to measure responses, without a 'don't know' or neutral point on the scale. However, participants were instructed to tick a box if they did not understand the question. Questions about knowledge included statements relating to how confident the respondents feel about assessing research methodology. The statements address perceived self-confidence in interpreting statistical tests, evaluating bias and assessing sample size. Answers were scored from ' 1 ' not confident at all to ' 6 ' very confident. Items on beliefs about EBP included statements such as 'EBP is essential in my practice', 'clinical judgement is more important than EBP' and 'I feel that I need more training in EBP'. Participants scored their answers on a range from ' $1-6$ ', with ' 1 ' indicating that they disagreed strongly with the statement and ' 6 ' suggesting that they agreed strongly with the statement [see Additional file 1].

The questionnaires were self-administered by the candidates on arrival to the teaching session. All data obtained were entered into a Microsoft Excel spreadsheet and exported for analyses using SPSS software version 14.0 (SPSS Inc., Chicago, IL., USA). The data then was coded and participants categorised into groups according to their background. Descriptive statistics were computed when possible. The data was summarized as counts (or percentages) occurring in the various response categories. Paired 
Likert-type items or sets of items were compared using nonparametric statistical techniques (e.g. chi-square homogeneity tests, Mann-Whitney-Wilcoxon U test) [22]. Differences on categorical measures were reported as $P$ value. The result was significant if $\mathrm{P}<0.05$. We compared responses from allied health care professionals with those from CAM practitioners.

\section{Results}

In total, 193 allied health care professionals and CAM practitioners completed the questionnaire. Of the respondents $121(62.7 \%)$ were allied health care professionals and $65(33.7 \%)$ practitioners stated that they work in the CAM field (7 missing responses). Furthermore, 91 $(47.1 \%)$ had qualified or had been working in their chosen health care fields within the last 10 years, whilst 82 $(42.5 \%)$ had been qualified or working for 11 years and over.
Figure 1 illustrates the respondents' background of exposure to research and EBP and current use of health research literature. It was found that the majority of the respondents had not attended a literature appraisal skills workshop $(87.3 \%)$ or received formal training in research methods $(69.9 \%)$, epidemiology $(91.2 \%)$ or statistics $(80.8 \%)$. However, $58(31 \%)$ stated that they had actually been personally involved in conducting some research activity. Questions regarding the participants' access to medical literature and evidence showed that only 60 $(32.1 \%)$ had access to a medical library. The majority of respondents stated that they did not search for medical literature on a regular basis (86.1\%), and only 75 (39.9\%) respondents reported that they read every week regularly to keep up to date with their professional literature.

Table 1 illustrates computer usage by allied health professionals and CAM practitioners. Far more CAM practition-

Prior exposure to research and evidence-based practice

\begin{tabular}{|c|c|c|}
\hline Have personally conducted research & 58 & 129 \\
\hline Previously attended statistic courses & 37 & 156 \\
\hline Previous epidemiology training & 17 & 176 \\
\hline Previous research methods training & 58 & 135 \\
\hline $\begin{array}{c}\text { Previously attended a literature } \\
\text { appraisal workshop }\end{array}$ & 24 & 165 \\
\hline
\end{tabular}

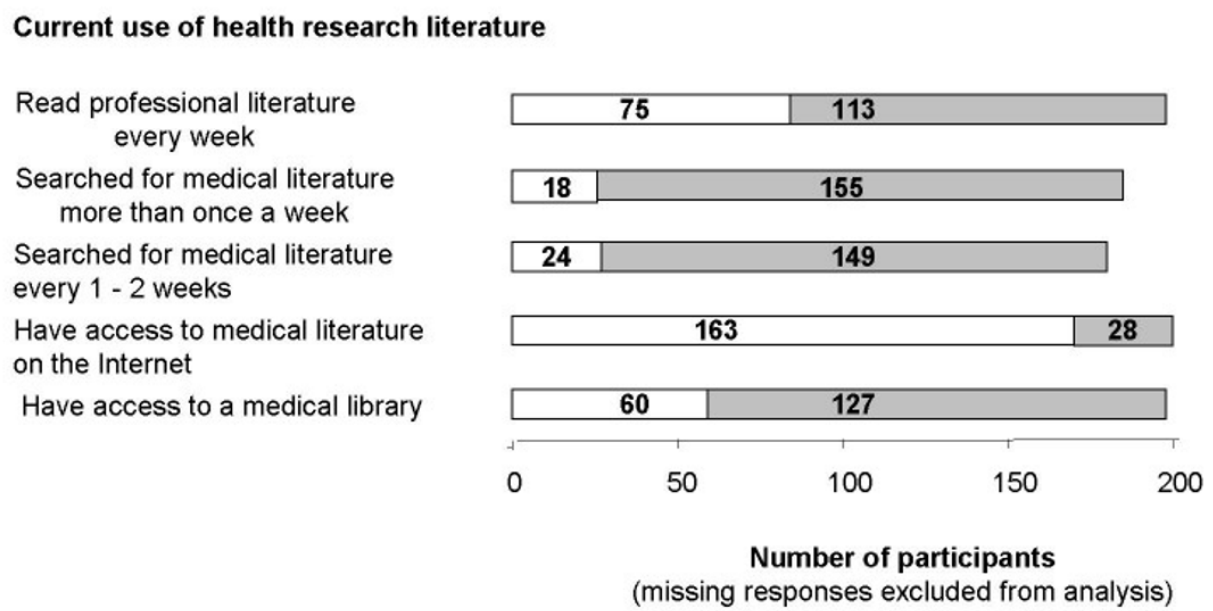

Figure I

Background of allied health care professionals and CAM practitioners' prior exposure to research and evidence-based practice and current use of health research literature. 
Table I: Background of allied health care professionals and complementary health practitioners concerning computer usage.

\begin{tabular}{|c|c|c|c|c|}
\hline & Total & $\mathbf{n}$ & $\%(\mathbf{n} / \mathbf{t})$ & $P$ value \\
\hline \multicolumn{5}{|l|}{ Access to the literature via Internet } \\
\hline Allied health professionals & 113 & 77 & 68.1 & 0.008 \\
\hline Complementary health practitioners & 64 & 61 & 95.3 & \\
\hline \multicolumn{5}{|l|}{ Access to a library } \\
\hline Allied health professionals & 115 & 42 & 36.5 & 0.015 \\
\hline Complementary health practitioners & 61 & 12 & 19.7 & \\
\hline \multicolumn{5}{|l|}{ Use of email 3 or more times a week } \\
\hline Allied health professionals & 121 & 67 & 55.4 & \\
\hline Complementary health practitioners & 65 & 59 & 90.8 & 0.001 \\
\hline \multicolumn{5}{|l|}{ Use of email discussion groups } \\
\hline Allied health professionals & 111 & 14 & 12.6 & 0.006 \\
\hline Complementary health practitioners & 63 & 19 & 30.2 & \\
\hline \multicolumn{5}{|l|}{ Surf the Internet more than once a week } \\
\hline Allied health professionals & 110 & 74 & 67.2 & 0.001 \\
\hline Complementary health practitioners & 65 & 61 & 93.8 & \\
\hline \multicolumn{5}{|c|}{ Search the Internet for information more than once a week } \\
\hline Allied health professionals & 112 & 97 & 86.6 & 0.001 \\
\hline Complementary health practitioners & 65 & 64 & 98 & \\
\hline
\end{tabular}

Total $=$ the total number of complete responses

$\mathbf{n}=$ the number of positive responses

Data missing from some respondents for each item due to incomplete responses

Only significant differences reported.

ers compared to allied health professionals accessed educational literature via the Internet $(95.3 \% \mathrm{v} 68.1 \%$, p $=0.008)$, used email on a regular basis $(90.8 \% \mathrm{v} 55.4 \%$, p $=0.001$ ) and explored and searched the Internet for information more than once a week $(93.8 \%$ v $67.2 \%, p=0.001$ and $98 \% \mathrm{v} 86.6 \%, \mathrm{p}=0.001$ respectively). However, both allied health professionals and CAM practitioners identified that a vast majority of them did not have access to a library or used email discussion groups in their work.

Respondents generally indicated that the majority of them did not feel confident at assessing research study design, generalisability, evaluating bias, sample size and statistical tests. Furthermore, $67.1 \%$ of practitioners felt that they had not had good or adequate training in EBM and $86.7 \%$ identified that they needed more training and education in the principles of EBM (Some confusion regarding the relationship between EBM and the process of clinical decision-making was found, with many practitioners feeling uncertain whether or not their own clinical judgement and patient choice should override the evidence. However, the majority of the practitioners agreed that they felt that EBM was essential to their practice $(75.6 \%)$ and not a passing fashion (74.6\%).
Respondents who reported that they had not previously attended a literature appraisal workshop stated that they felt that they needed more training in EBM compared to those that had $(91.4 \% \mathrm{v} 72.7 \%, \mathrm{p}=0.007)$, but felt that EBM has little impact on their clinical practice $(26.4 \% \mathrm{v}$ $50 \%, \mathrm{p}=0.33$ ). The respondents who reported that they had not been involved in conducting any type of research also felt that they needed more training in EBM than those who had been involved in any research activity. However, the result was not statistically significant $(91.2 \%$ v $84.5 \%$, $\mathrm{p}=0.09)$.

Table 2 examines the effect of years since qualification on practitioners' beliefs relating to EBM. We used the threshold of 11 years and over as it is unlikely that CAM practitioners who have been qualified for over ten years would have received teaching in EBP as part of their initial training. Practitioners with more than 11 years experience stated that they had not had good training previously in $\operatorname{EBM}(\mathrm{p}=0.04)$ and they felt that original research papers were confusing $(\mathrm{p}=0.02)$ more often than their less experienced counterparts. The more experienced practitioners also felt that clinical judgment was more important than EBM ( $p=0.005)$ than those with shorter length of time since qualification. More allied health care professionals stated that EBM was essential for their clinical practice and 
Table 2: Effect of profession and years since qualification ( $<5$ years, $6-10$ years, I I years and over) on allied health care professionals and complementary health practitioners' beliefs relating to Evidence-based Medicine (EBM)

\begin{tabular}{|c|c|c|c|c|}
\hline Question & Total & $\begin{array}{c}\text { Disagree (strongly to slightly) with } \\
\text { the statement } \mathbf{n}(\%)\end{array}$ & $\begin{array}{l}\text { Agree (strongly to slightly) with the } \\
\text { statement n (\%) }\end{array}$ & $P$ value \\
\hline \multicolumn{5}{|l|}{ Years since qualification } \\
\hline \multicolumn{5}{|l|}{ I find original work confusing } \\
\hline 5 years and under qualified & 37 & $21(56.7)$ & $13(35.1)$ & \\
\hline $6-10$ years qualified & 33 & $21(63.6)$ & I (3) & 0.02 \\
\hline II years and over qualified & 66 & $30(45.4)$ & $30(45.4)$ & \\
\hline OVERALL & 136 & 72 (52.9) & $44(32.3)$ & \\
\hline \multicolumn{5}{|l|}{ Clinical judgement more important } \\
\hline 5 years and under qualified & 39 & $18(46.1)$ & $21(53.8)$ & \\
\hline $6-10$ years qualified & 36 & II (30.5) & $21(58.3)$ & 0.005 \\
\hline II years and over qualified & 75 & $33(44)$ & $36(48)$ & \\
\hline OVERALL & 150 & $62(41.3)$ & $78(52)$ & \\
\hline \multicolumn{5}{|l|}{ I had good EBM training } \\
\hline 5 years and under qualified & 39 & $27(69.2)$ & $12(30.7)$ & \\
\hline $6-10$ years qualified & 34 & $20(58.8)$ & II (32.3) & 0.04 \\
\hline II years and over qualified & 76 & $53(69.7)$ & $15(19.7)$ & \\
\hline OVERALL & 149 & $100(67.1)$ & $38(25.5)$ & \\
\hline \multicolumn{5}{|l|}{ Profession } \\
\hline \multicolumn{5}{|l|}{ EBM is essential for my practice } \\
\hline Allied health professionals & 112 & $16(14.2)$ & 91 (8I.2) & 0.02 \\
\hline Complementary health practitioners & 60 & $19(31.6)$ & $39(65)$ & \\
\hline OVERALL & 172 & $35(20.3)$ & $130(75.6)$ & \\
\hline \multicolumn{5}{|l|}{ I need more training in EBM } \\
\hline Allied health professionals & 114 & $12(10.5)$ & $98(85.9)$ & 0.05 \\
\hline Complementary health practitioners & 66 & $8(12.9)$ & $58(93.5)$ & \\
\hline OVERALL & 180 & $20(11.1)$ & $156(86.7)$ & \\
\hline
\end{tabular}

Total $=$ total number of respondents with complete responses

$\mathbf{n}=$ number of responses

$\%=$ percentage of total with complete responses

Data missing from some respondents for each item due to incomplete responses

Only significant differences reported.

also that they needed more training in EBM than CAM practitioners $(\mathrm{p}=0.02$ and $\mathrm{p}=0.05$ respectively).

\section{Discussion and Conclusion}

Our study identified several issues that require addressing in the provision of EBP training for allied health care professionals and CAM practitioners. Amongst allied and CAM practitioners the perceived need to obtain training in EBM was high and perception of competence was low. Comparatively, allied health care professionals and those with longer length of time since qualification fared worse than CAM practitioners and those with recent qualification respectively. Furthermore, learning needs varied according to the type of profession, time since graduation and prior research experience.
To ensure the validity and generalisability of our findings, we selected questions from reliable and previously validated questionnaires $[18,19]$. One of the strengths of our study is that we surveyed a large sample of both allied health care professionals and CAM practitioners from a variety of professions and with varying lengths of time since qualification. However, we did not employ a random sampling process and the sample was from participants who voluntarily attended the courses. Therefore our sample was restricted to those individuals who may have been more aware and self-motivated than other practitioners. Furthermore, our respondents were all based within the West Midlands region and as such our findings may not entirely reflect the knowledge and beliefs of other allied health care professionals and CAM practitioners outside of the region. We, therefore, acknowledge that the generalisability of our findings may be limited but our 
study does provide a starting point for further research in these groups of practitioners. However, we feel that our findings do merit consideration by teachers and trainers in these health care fields and in particular those providing continuing professional development training programmes.

Our survey suggests that like previous studies $[18,19,23]$ that found that medical doctors lack methodological competence in critical appraisal skills and EBM, CAM practitioners and allied health care professionals also need skills. Our survey also correlates with the findings of a previous study [19] where we examined medical doctors' knowledge and beliefs concerning EBM. We found that doctors within our deanery also reported that they did not feel confident at assessing study design, generalisability of the research or evaluating sample size and statistical tests. Furthermore, many junior doctors stated that they support the principles of EBM, but they are undecided regarding whether patient choice and their own clinical judgment are more important and should override research evidence. The doctors were also in agreement with the allied health care professionals and CAM practitioners and confirmed that EBM was essential to their practice but they felt that they required further training in the subject. It is therefore, apparent that both groups have identified that EBP training is important and has not previously met their needs.

Our survey findings are exploratory and will benefit from further replication, but it does provide information for allied health care professionals' and CAM practitioners' teachers and trainers. In particular, our findings should be taken into consideration when planning EBP curricula as it is important to tailor teaching to the needs of specific subgroups of trainees to ensure that specific learning needs are met.

\section{Competing interests}

The authors declare that they have no competing interests.

\section{Authors' contributions}

$\mathrm{JH}$ contributed to the questionnaire design, co-ordination and collection of the data and drafted the manuscript. IH performed the statistical analysis and helped to draft the manuscript. KSK conceived the study, and participated in its design and contributed to the write up of the manuscript. All authors read and approved the final manuscript.

\section{Additional material}

\section{Additional file 1}

Copy of developed questionnaire. A copy of the developed questionnaire used to measure allied health care professionals and CAM practitioners' basic knowledge, skills and beliefs concerning the main principles of EBP. Click here for file

[http://www.biomedcentral.com/content/supplementary/14726882-8-45-S1.doc]

\section{Acknowledgements}

The courses were funded from a grant received from the Learning and Skills Council and European Social Fund (European Union Grant LSE3 I068WM2).

We would like to thank Dr James Davis, Dr Arri Coomarasamy and Miss Denise Hardy for all of their help and assistance in this project.

\section{References}

I. Dawes M, Summerskill W, Glasziou P, Cartabellotta A, Martin J, Hopayian K, Porzsolt F, Burls A, Osborne J: Sicily statement on evidence-based practice. BMC Medical Education 2005, 5: I.

2. The Foundation Programme Committee: Curriculum for the foundation years in postgraduate education and training. Department of Health; 2005.

3. General Dental Council: Standards for Dental Professionals. 2005 [http://www.bda.org].

4. Health Professionals Council: Standards of proficiency: Arts therapists. [http://www.hpc-uk.org].

5. Health Professionals Council: Standards of proficiency: Dietitians. 2003 [http://www.hpc-uk.org].

6. Health Professionals Council: Standards of proficiency: Radiographers. 2003 [http://www.hpc-uk.org].

7. Health Professionals Council: Standards of proficiency: Speech and language therapists. 2003 [http://www.hpc-uk.org].

8. Health Professionals Council: Standards of proficiency: Chiropodists/Podiatrists. 2005 [http://www.hpc-uk.org].

9. Health Professionals Council: Standards of proficiency: Physiotherapists. 2005 [http://www.hpc-uk.org].

10. Nursing and Midwifery Council: The NMC code of professional conduct: standards for conduct, performance and ethics. 2004 [http://www.nmc-uk.org].

II. General Osteopathic Council: Standard 2000: Standard of proficiency. 1999 [http://www.osteopathy.org.uk].

12. The Aromatherapy Council: National Occupational Standards for Aromatherapy. 2006 [http://www.aromatherapycouncil.co.uk/ ].

13. General Chiropractic Council: Code of Conduct and Standard of Proficiency. 2005 [http://www.gcc-uk.org].

14. House of Lords: Science and Technology - sixth report: Complementary and Alternative Medicine. 2000 [http://www.parlia ment.the-stationery-office.co.uk].

15. Hadley J, Davis J, Khan KS: Teaching and learning evidencebased medicine in complementary, allied and alternative health care: An integrated tailor-made course. Journal of Alternative and Complementary Medicine 2007 in press.

16. Harden RM: Ten questions to ask when planning a course or curriculum. Med Educ 1986, 20:356-365.

17. Morrison J: ABC of learning and teaching in medicine: Evaluation. BMJ 2003, 326:385-387.

18. Awonuga AO, Dwarakanath LS, Khan KS, Taylor R: Post-graduate obstetrics \& gynaecology trainees' views and understanding of Evidence-based Medicine. Medical Teacher 2000:27-29.

19. Hadley J, Wall D, Khan KS: Learning needs analysis to guide teaching evidence-based medicine: knowledge and beliefs 
amongst trainees from various specialities. BMC Med Educ 2007, 7:II.

20. Taylor R, Reeves B, Mears R, Keast J, Binns S, Ewings P, Khan KS: Development and validation of a questionnaire to evaluate the effectiveness of evidence-based practice teaching. Medical Education 200I, 35:544-547.

21. Fritsche L, Greenhalgh T, Falck-Ytter Y, Neumayer HH, Kunz R: Do short courses in evidence based medicine improve knowledge and skills? Validation of Berlin questionnaire and before and after study of courses in evidence based medicine. BMJ 2002, 325: |338-|34|.

22. Clason DL, Dormondy T]: Analyzing data measured by individual likert-type items. Journal of Agricultural Education 1994, 35:3I-35.

23. Olatunbosun OA, Edouard L, Pierson RA: Physicians' attitudes toward evidence based obstetric practice: a questionnaire survey. $B M J$ I 998, 3 I6:365-366.

\section{Pre-publication history}

The pre-publication history for this paper can be accessed here:

http://www.biomedcentral.com/1472-6882/8/45/prepub

Publish with Bio Med Central and every scientist can read your work free of charge

"BioMed Central will be the most significant development for disseminating the results of biomedical research in our lifetime. "

Sir Paul Nurse, Cancer Research UK

Your research papers will be:

- available free of charge to the entire biomedical community

- peer reviewed and published immediately upon acceptance

- cited in PubMed and archived on PubMed Central

- yours - you keep the copyright 